\title{
Numerical Study of a Left Ventricular Assist Device (LVAD) With Different Blade Heights and Tip Clearances
}

\section{Muhammad Rashidi Abdul Kadir ${ }^{1}$, Mohammad Azim Abdul Aziz ${ }^{1}$, Mohammad Hasbullah Padzillah", ${ }^{2,5}$ Mohammad Nor Harun,, Kahar Osman ${ }^{2,3}$, Aizai Azan Abdul Rahim ${ }^{4}$, Mohamed Ezani Abdul Taib ${ }^{4}$ and Ahmad Zahran Md Khudzari $^{13^{*}}$}

\author{
${ }^{1}$ School of Biomedical Engineering and Health Sciences, Faculty of Engineering, Universiti Teknologi Malaysia, \\ 81310 Skudai, Johor, Malaysia \\ ${ }^{2}$ School of Mechanical Engineering, Universiti Teknologi Malaysia, 81310 Skudai, Johor, Malaysia \\ ${ }^{3}$ IJN-UTM Cardiovascular Engineering Centre, Institute of Human Centered Engineering, Universiti Teknologi \\ Malaysia, 81310 Skudai, Johor, Malaysia \\ ${ }^{4}$ Institut Jantung Negara, 50400 Kuala Lumpur, Malaysia \\ ${ }^{5}$ UTM-Centre for Low Carbon Transport (Locartic), Institute of Vehicle System and Engineering, Universiti Teknologi \\ Malaysia, 81310 Skudai, Johor, Malaysia \\ ${ }^{6}$ Sports Innovation Technology Centre, Institute of Human Centered Engineering, Universiti Teknologi Malaysia, \\ 81310 Skudai, Johor, Malaysia
}

Received 1 March 2018; accepted 28 July 2018, available online 5 August 2018

\begin{abstract}
One treatment modality for heart failure is to employ a mechanical heart assist device to increase blood flow to peripheral organs. There are various kinds of axial and centrifugal type mechanical pumps available for implantation depending on patient condition. Axial pumps are smaller in size comparatively, although centrifugal pumps have the advantages of lower rotational speed as well as better maintaining any native blood flow pulsatility. This work presents the results of the numerical study of the centrifugal blood pump configured as a Left Ventricular Assist Device (LVAD). The pump design utilized standard industrial centrifugal pump design principles but applied to smaller sized blood pumps. Flow characteristics are modelled using 3-dimensional steady state models operating at design speed of $2000 \mathrm{rpm}$ using Newtonian blood properties for the fluid. Two design parameters of the pump are studied, the impeller blade height and tip clearance resulting in nine model variants. Analysis includes the hydrodynamic performance of the pump and the flow characteristics in the pump. A haemolysis prediction model quantifying red blood cell stress from exposure time and shear stress was used for quantitative predictions of haemolysis within the blood pump. Blood damage estimation was calculated along each path-line and averaged to a single value. By using a ranked selection method, the model with the $15 \mathrm{~mm}$ blade height and $800 \mu \mathrm{m}$ tip clearance was selected as the preferred configuration with Haemolysis Index of $0.01 \mathrm{mmHg}$, efficiency of $58 \%$ at $104 \mathrm{mmHg}$ outlet pressure.
\end{abstract}

Keywords: Computational Fluid Dynamics; Left Ventricular Assist Device; Blade height; Blade tip clearance; Haemolysis.

\section{Introduction}

Heart failure is a cardiac disease that has been increasing year-on-year. It is estimated that 3 million patients in US experienced chronic heart failure in 1995 [1]. In 2001, cases increased to around 5 million [2]. Fifty percent of patients diagnosed with congestive heart failure (CHF) die within one year and seventy percent within five years $[3,4]$. Heart failure impairs the ability of the ventricle to fill or eject blood [5], causing insufficient cardiac output to meet the requirement of the body. Congestive heart failure is caused by many factors that damage the heart muscle; one example is coronary artery disease (CAD) wherein arteries are blocked or severely narrowed causing decreased blood flow to the heart muscle and which may lead to myocardial infarction. Infections, alcohol or drug abuse also can cause damage the muscle of the heart. Although heart transplantation remains the most successful long-term treatment for late stage heart failure, the limited number of donors in most regions of the world restricts its widespread adoption. Due to such limitation, Ventricular Assist Devices (VAD) have become a promising alternative treatment [6]. It has become an established 
alternative for patients with advanced heart failure either as temporary bridge to transplant or as a more permanent destination therapy. The increasing number of cases of the end-stage heart failure raises the demand for the use of mechanical assist devices such as VADs. Laterdeveloped blood pumps contribute to a more permanent alternative therapy for the end stage heart failure. A ventricular assist device functions in parallel to the weakened heart and can be used to assist either the right (RVAD), left ventricle (LVAD) or both (BiVAD) [6].

Computational Fluid Dynamics (CFD) has often been used to study the flow fields in blood pumps to estimate pump performance and blood damage potential in the design stages where such data is useful for comparison and selection of one pump design over another. There have been many studies related to improving performance of blood pumps by varying several parameters in the geometries of their designs - mostly the impeller as it is one fundamental part of a blood pump - although the multiple parameters affect the overall performance making the determination of best design less than intuitive[6]. Parameters like impeller blade curvature, length of blade tip and blade angles for example have been studied for various pump designs and have been shown to affect performance, flow characteristics, and blood damage potential[6]. Other parameters such as blade height of the impeller, despite being known to have a significant performance effect on industrial pump [7], are less studied for blood pumps especially with respect to blood damage. Therefore blade height is a chosen parameter of this study to investigate its effect on overall performance. Tip clearance is one of the most studied parameters and is known to affect pump efficiency and blood damage potential [8-10]. The tip clearance is a narrow gap that separates the impeller from the pump casing. This tip clearance is a channel for secondary flow and a potential region for blood damage due to high shear stresses and long residence times. Tip clearance is the second parameter chosen for study due to its significant effect on blood damage potential and its relevance to the blade height.

The pump design process of this study utilized standard existing industrial centrifugal pump principles extrapolated down to the sizes needed for a blood pump. Two design parameters of the pump were studied; the impeller blade height and tip clearance. Flow characteristics are modelled using 3-dimensional steady state models operating at design speed of $2000 \mathrm{rpm}$ using Newtonian blood properties for the fluid. Based on the selected parameters, nine model variants were studied. Analysis includes the hydrodynamic performance of the pump, flow characteristics, and blood damage potential. There are several design criteria to take into consideration. The most basic requirement any VAD has to fulfil is the flow output. For an adult $\mathrm{CHF}$ patient, the VAD should be able to deliver 4-6 L/min at 100-120 mmHg pressure rise[11, 12]. The normal human blood pressure in the left ventricle is within $80 \mathrm{mmHg}$ to 120 $\mathrm{mmHg}$ where the average blood pressure or the mean arterial pressure (MAP) is approximately $100 \mathrm{mmHg}$ where the blood pump must produce to ensure sufficient blood to be transferred to the whole body[13]. From a hemo-compatibility stand point, attention should be given to potential region of thrombosis where recirculation or stagnation flow occurs. Blood flow must be constantly in motion throughout an on-obstructing flow path. Furthermore, the damage to blood particles is also an important design consideration in blood pumps [14] and von-Willebrands Factor (vWF) is one such parameter which is receiving a lot of attention at present [15].

In this study, the effect of varying blade height and tip clearance of a centrifugal blood pump design on hemodynamic performance was investigated. It was hypothesized that there could be an optimum configuration from both heights of the impeller blade and tip clearance between casing and impeller blade. There was evidence that indicates the tip clearance between rotating impeller and stationary pump casing affects the level of haemolysis of the blood pump [16]. Meanwhile, the impeller blade height parameter will likely affect the performance of the blood pump as it will have an effect on wall shear stresses in the flow passages on the rotor. A numerical approach was used to study the effects of these two parameters on the blood pump performance and also on the potential blood damage. An optimum configuration is obtained through evaluation method of key performance parameters involving a scoring method.

\section{Methodology}

For use as a blood pump, it is desirable to make pump casing as small as possible while meeting the flow requirement of the circulatory system. A centrifugal configuration was chosen because centrifugal designs can operate over a wide range of flow while exhibiting small change in pressure head. Due to the lack of stator vanes to guide the flow, centrifugal designs are less sensitive to off-design conditions [17]. Geometries of the blood pump were calculated based on a selected impeller operating speed of $2000 \mathrm{rpm}$. Additional design parameters chosen are a pressure rise of $100 \mathrm{mmHg}$ and $5 \mathrm{~L} / \mathrm{min}$ flow rate at design point.[13].The pump impeller diameter based on this operating speed is $44.8 \mathrm{~mm}$. Table 1 summarizes the design parameters for the pump geometry for both the impeller and the volute casing of the pump.

As mentioned, two design factors are studied; the impeller blade height and tip clearance as illustrated in Fig 1. From a mechanical aspect, pumps favour tight tolerance of the impeller blade tip clearance for efficient performance and prevent loses due leakage flow. Alternatively, functioning as a blood pump, additional considerations that affect the blood particle are taken into consideration as it oppositely favours looser tolerances and possibly lower impeller blades for better washout to prevent stagnant flow region and potential high shear stresses on the blood particles. Therefore, blade height and tip clearance are the parameters involved in this study.

Based on these two parameters, there are a total of nine variants involved in this study. Three blade heights were selected: $10 \mathrm{~mm}, 15 \mathrm{~mm}$, are and $20 \mathrm{~mm}$ as in Fig 2. 
Three values were also selected for the tip clearance parameter; $300 \mu \mathrm{m}, 500 \mu \mathrm{m}$, and $800 \mu \mathrm{m}$ as in Fig 3. The study conducted was carried out using the full factorial design method $\left(3^{2}=9\right)$ to obtain an optimum configuration. Fig. 4 illustrates the parameters chosen for the study and the model variations.

Table 1: Geometrical details of blood pump model.

\begin{tabular}{lcc}
\hline Component & Parameter (unit) & Value \\
\hline Impeller & Vane Number & 7 \\
& Vane Inlet Angle $\left(^{\circ}\right)$ & 41.8 \\
& Vane Outlet Angle $\left(^{\circ}\right)$ & 70.0 \\
& Vane Inlet Thickness & 1.0 \\
& $(\mathrm{~mm})$ & \\
& Vane Outlet Thickness & 2.0 \\
& $(\mathrm{~mm})$ & \\
\hline \multirow{4}{*}{ Volute } & Inlet Diameter $(\mathrm{mm})$ & 12.2 \\
& Outer Diameter $(\mathrm{mm})$ & 44.8 \\
& Throat Area, $\mathrm{A}_{\mathrm{th}}\left(\mathrm{mm}{ }^{2}\right)$ & 39.0 \\
& Base Diameter, $\mathrm{D}_{3}(\mathrm{~mm})$ & 47.7 \\
& Volute Height, $\mathrm{b}_{3}(\mathrm{~mm})$ & 1.57 \\
Volute Angle, $\mathrm{a}_{\mathrm{v}}\left({ }^{\circ}\right)$ & 9.15 \\
\hline
\end{tabular}

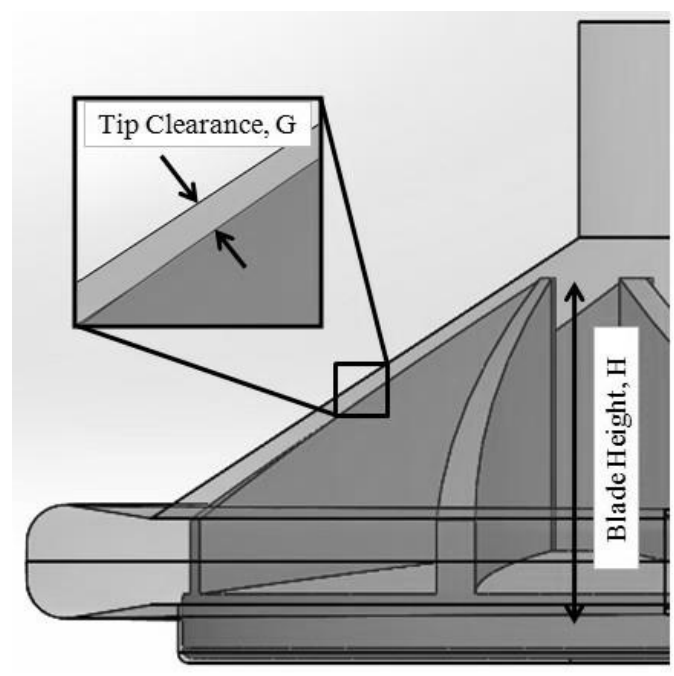

Fig 1: The design factors selected for study.

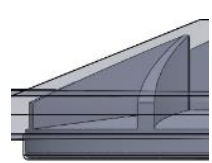

(a)

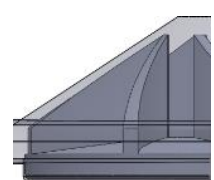

(b)

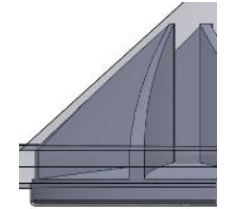

(c)
Fig 2: Blade height model variations; (a) $10 \mathrm{~mm}$ (b) $15 \mathrm{~mm}$ (c) $20 \mathrm{~mm}$

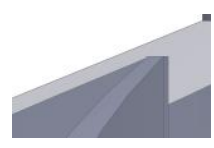

(a)

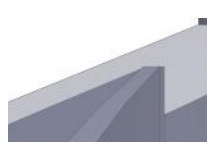

(b)

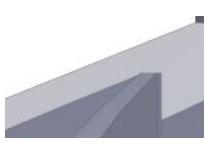

(c)
Fig 3: Tip clearance model variations for $10 \mathrm{~mm}$; (a) $300 \mu \mathrm{m}$ (b) $500 \mu \mathrm{m}$ (c) $800 \mu \mathrm{m}$

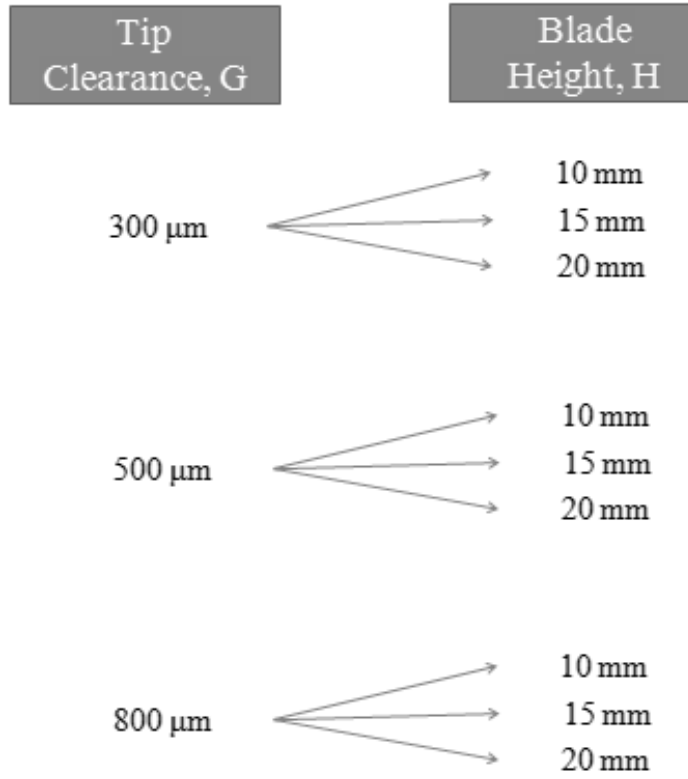

Fig. 4: Overall model variants involved in study.

\subsection{Description of Numerical Model}

The $3 \mathrm{~d}$ modelling of the blood pump geometries were modelled using SOLIDWORKS (Dassault Systèmes SolidWorks Corp., Waltham, MA, USA)which was exported to software ANSYS (ANSYS Inc., Canonsburg, PA, USA) for mesh generation and boundary condition setup. Mesh generation is a vital consideration in CFD simulation as it affects the accuracy and consistency of the results and quantity of errors associated with spatial discretization. Tetrahedral meshes were used in this study for the entire flow domain.

The overall mesh quality for each of the model variations was ensure to be within acceptable range particularly the skewness and the aspect ratio. The skewness of the meshes were below 0.33 on average while not exceeding the maximum of 0.95 . The aspect ratio were kept below 10 in overall based on the recommendations of best meshing practice [18]. Additionally, the wall functions $(\mathrm{y}+)$ considered for this study for the SST turbulence model, the $\mathrm{y}+$ value is ensured to be close to 1 as possible for areas that are significant in the study such as the tip clearance and the impeller blades impeller while keeping the overall y+ close to 5 .

The Multiple Reference Frame (MRF) or the 'frozen rotor' method was used to simulate the rotating impeller. The model geometry was divided into 3 domains; the inflow, the impeller region (rotating region) and the volute region as illustrated in Fig. 5. A non-slip boundary condition was imposed on the walls of the models. The MRF method is a steady state approximation of motion of the pump impeller where the motion of the moving part is observed through the instantaneous flow field with the pump impeller in a static position as the grid remains fixed for the computation. Hence, this approach is referred to as the 'frozen rotor' approach. 


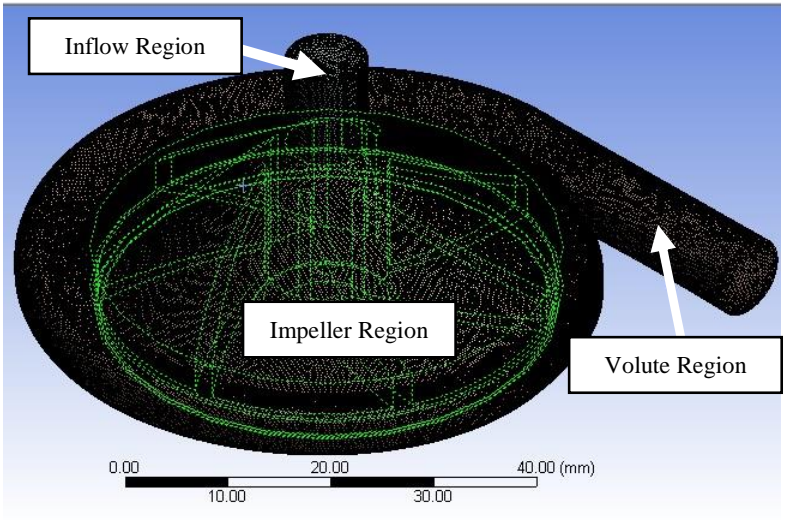

Fig. 5: Mesh of pump model with 3 boundary zones (Inflow, Impeller, Volute).

\subsection{Boundary Condition}

Throughout the simulation, a constant angular speed of $2000 \mathrm{rpm}$ was imposed. The fluid modelled in this study was a Newtonian fluid with density and viscosity similar to human blood. Blood can be considered a Newtonian fluid in VAD calculations as the shear rates found in blood pumps is higher than $100 \mathrm{~s}^{-1}$, therefore an asymptotic viscosity of blood is assumed with constant viscosity [19]. The viscosity of the blood used was 0.035 Pa.s with a density of $1060 \mathrm{~kg} / \mathrm{m}^{3}$. The flow parameters of all numerical models were set at inlet of $0 \mathrm{mmHg}$ and outflow rate of $5 \mathrm{~L} / \mathrm{min}$ at the operating speed of 2000 rpm. The shear stress turbulence (SST) model was selected for this study. The SST model was developed to effectively blend the robustness and accuracy of formulation of the k- $\omega$ model in the near-wall region with the freestream independence of the $k-\varepsilon$ model in the far field. The SST model is known to perform well in estimating flow separation under adverse pressure gradient. The pump performance indexes used in this study were tip-leakage flow, hydraulic performance, and pump efficiency, while blood damage estimation were also investigated to quantify the effect on red blood cells.

\subsection{Blood Damage Equation}

As mentioned earlier, blood damage is a function of the magnitude of shear stress and the time exposure to such shear stress. Monitoring the stress level on the blood cells as it travels through the pump is important to assess accumulated damage on blood cells. Blood damage estimation is computed along pathlines of the computed flow field through the pump. They represent the paths travelled by the blood cells while the pump is operating. Although haemolysis is related to many factors, previous studies have based haemolysis estimation on the contribution of the shear stress and exposure time of a blood particle [20-22]. Various numerical approaches have been conducted to quantify shear-induced haemolysis. The most commonly used is the power law equation developed by[20]; a simple but effective correlation between shear stress as shown in the equation (1):
$\frac{\Delta \mathrm{Hb}}{\mathrm{Hb}}=C t^{\alpha} \tau^{\beta}$

where $\Delta \mathrm{Hb} / \mathrm{Hb}$ quantifies blood damage sustained by the blood cell, $\tau$ is the shear stress and $t$ is the exposure time of that shear stress, while $\alpha, \beta$, and $\mathrm{C}$ are constant values. The power law equation provides an acceptable prediction for comparison purposes between designs as this approach usually tends to over-estimate the haemolysis index values. It was later proposed by [22] that summing the individual contributions along a pathline does not account for shear history of the red blood cells in which an already stressed cell membrane may be damaged more as the stress is maintained. It was proposed that a different approach that redefines the blood damage in term of mechanical dose, $\mathrm{D}$ function as:

$$
D=t \cdot \tau^{\frac{\beta}{\alpha}}
$$

Thus, the term is substituted into equation (1):

$$
\begin{aligned}
& \frac{\Delta \mathrm{Hb}}{\mathrm{Hb}}=C \alpha \quad t^{\alpha}{ }^{1} \tau^{\beta} d t \\
& \frac{\Delta \mathrm{Hb}}{\mathrm{Hb}}=\sum_{i=1}^{N} C \alpha \quad \sum_{j=1}^{i} \tau\left(t_{j}\right)^{\beta / \alpha} \Delta t^{\alpha 1}{ }^{1} \tau\left(t_{i}\right)^{\beta / \alpha} \Delta t
\end{aligned}
$$

where $\Delta \mathrm{Hb} / \mathrm{Hb}$ quantifies blood damage sustained by the blood cell in the $i^{\text {th }}$ interval, $\mathrm{N}$ is the number of observation time intervals along the fluid pathline, $\tau$ is a function of stress that varies with position along the pathline. The term in the brackets represents the mechanical dose moving along the pathline from the starting time until the $\mathrm{i}^{\text {th }}$ instant, the weighted summation of $\Delta t_{j}$ from $t_{0}$ to $t_{i}$. The values of constants used in this investigation are adopted from a recent blood damage study [12] that uses the constants proposed by Taskin et al. [23] , $\alpha=0.747, \beta=2.004 \mathrm{C}=0.0000121$.

\subsection{Optimum Model Evaluation Method}

There are several ways of obtaining an optimized model configuration out of almost infinite variations such as using Taguchi Method [24], Response Surface Method $[25,26]$, ranked selection method [27, 28]. In this study, screening and scoring method is used. Using a full factorial design of experiment (DOE) method, with two design factors; 1) blade height and 2) tip clearance, in which both have three levels, amounting to a total of nine model variants $\left(3^{2}=9\right)$ were generated as illustrated in Error! Reference source not found.. The selection for one model variant superior among the others was done using an evaluation method typically used for product design evaluation in industry, in the form of a screening and scoring method $[27,28]$ with some modifications to suit the needs of the study. The selection and screening method required a benchmark against which the variants were compared to (in selection stage) that was excluded in this study. The selection method was simplified for 
comparison between model variants, where each simulation output were multiplied to a fraction based on weighting scale. The weighting values are illustrated in Table 2. The superior model variant was the model with the smallest net value from all parameters.

Table 2: Weighting value given to result output of model variants.

\begin{tabular}{lc}
\multicolumn{1}{c}{ Parameters } & Weighting (\%) \\
\hline Haemolysis, HI & 35 \\
Average Leakage Flow, LF & 30 \\
Pressure Output, $\mathrm{P}_{\text {out }}$ & 25 \\
Pump efficiency, $\eta$ & 10 \\
\hline
\end{tabular}

\section{Results and Discussion}

\subsection{Model Validation}

The validation of the models involved in the study was validated against the results of similar design feature of the pump particularly the impeller diameter [29]. Day et al. published a study of a $46 \mathrm{~mm}$ diameter, 5-blade pump which in contrast to the current study that features a $44.8 \mathrm{~mm}$ diameter, 7-blade impeller. The comparison was chosen due to their similar impeller size, despite the fact that a comprehensive detail of the impeller and volute designs and specific geometries are not known except certain key parameters like the impeller diameter, and operating speed.

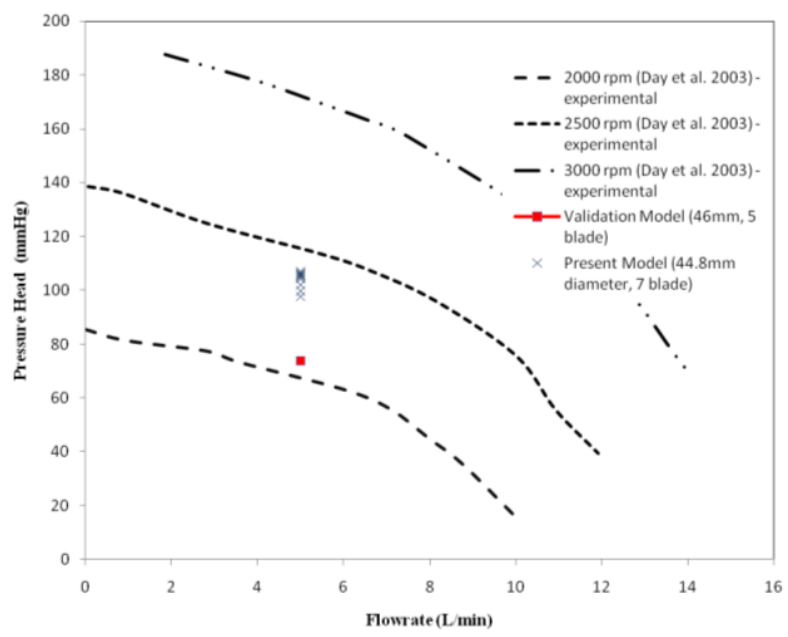

Fig. 6: Haemolysis Index comparison curve against blade height for studied tip clearances.

Regardless, comparison was made with a validation model, which is the same model as the present study but with differing impeller diameter and blade number. Fig. 6 illustrates the comparison of a selected previous publication with the current study. Apparently, the plot of the current model for $2000 \mathrm{rpm}$ follows closely with the experiment data with minor differences. The relative differences of less than 10 percent is obtained at studied flowrate of $5 \mathrm{~L} / \mathrm{min}$.

\subsection{Blood Damage Estimation (Haemolysis Index)}

The magnitude of wall shear stress and the time exposure to such shear are essential parameters to consider in determining the blood damage levels [30]. It is required of the numerical model to track each individual particle as it travels through the blood pump. For this purpose, Lagrangian particle tracking was used. Particles were released from the inlet of the pump at random position at the inlet boundary. The haemolysis was calculated for each path-line and that results to a single haemolysis index to represent that particular pump model. Since the study is a steady state simulation the calculation of haemolysis is for one flow pass through the pump. 20000 particles were chosen based on a previous study of a similar application [12]. The particle number is said to be adequate to generate statistically significant noise-free predictions of the haemolysis index for similar work in the same application. Therefore, haemolysis index calculation was done for all other models with the selected particle number for comparison.

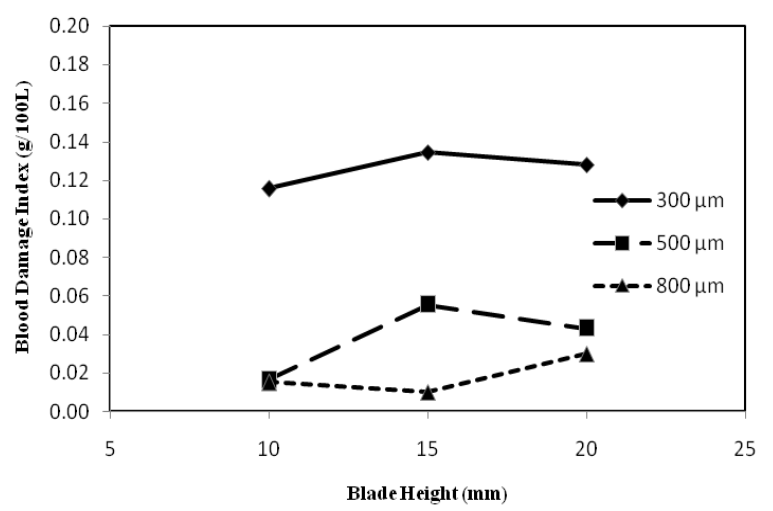

Fig. 7: Haemolysis Index comparison curve against blade height for studied tip clearances.

Fig. 7 and Table 3 illustrates the plot and data of haemolysis index with increasing blade height for three different tip clearances respectively. The range of haemolysis index varies from $0.015 \mathrm{~g} / 100 \mathrm{~L}$ until 0.134 $\mathrm{g} / 100 \mathrm{~L}$ from all variants. Higher haemolysis index value can be seen contributed by smaller tip clearance (300 $\mu \mathrm{m})$. Thus it can be seen that tip clearance has more apparent effects on haemolysis as compared to blade height. The smaller tip clearance of $300 \mu \mathrm{m}$ produced the largest haemolysis index significantly as compared other variations by 36 percent with an average value of 0.12 $\mathrm{g} / 100 \mathrm{~L}$. Despite $500 \mu \mathrm{m}$ models have a higher haemolysis index $(0.03 \mathrm{~g} / 100 \mathrm{~L})$ than $800 \mathrm{um}$ models $(0.01 \mathrm{~g} / 100 \mathrm{~L})$, the differences is a mere 0.5 percent. For the effect of blade height, the lowest blade height $(10 \mathrm{~mm})$ produced the lowest haemolysis index with an average of 0.04 $\mathrm{g} / 100 \mathrm{~L}$ while the higher blade heights $(15 \mathrm{~mm}$ and $20 \mathrm{~mm})$ produced similar haemolysis index at a slightly higher value of $0.06 \mathrm{~g} / 100 \mathrm{~L}$.

From the perspective of blood damage index, the effect of blade height within the studied range has minor effects although in overall the lowest blade height does exhibits a slightly lower haemolysis index in comparison to the higher blade heights $(15 \mathrm{~mm}$ and $20 \mathrm{~mm}$ ). Tip clearance however has a more apparent on 
blood damage potential for the studied range. Smaller tip clearances increase the cumulated shear stresses resulting in heighten blood damage potential.

Table 3: Data of Haemolysis Index at rotating speed 2000 rpm and outflow $5 \mathrm{~L} / \mathrm{min}$.

\begin{tabular}{ccccc}
\hline $\begin{array}{c}\text { Haemolysis Index } \\
(\mathrm{g} / 100 \mathrm{~L})\end{array}$ & \multicolumn{4}{c}{ Blade Height $(\mathrm{mm})$} \\
\hline $\begin{array}{c}\text { Tip Clearance } \\
(\mu \mathrm{m})\end{array}$ & 10 & 15 & 20 & Mean \\
\hline 300 & 0.115 & 0.134 & 0.128 & 0.12 \\
500 & 0.016 & 0.055 & 0.042 & 0.03 \\
800 & 0.015 & 0.012 & 0.035 & 0.01 \\
Mean & 0.04 & 0.06 & 0.06 & \\
\hline
\end{tabular}

\subsection{Flow Characteristics - Tip Leakage Flow}

Analysis of the flow patterns within the impeller blade tip clearance region is an important consideration as it affects both the hydraulic performance and potential for blood damage. Fig. 8 and Table 4 illustrates the mean leakage flow through impeller tip clearances against the impeller blade height. The trend illustrates a decreasing tip leakage flow with increasing blade height by 45 percent with each incremental blade height. Additionally, between tip clearances the trend is mostly apparent that the smaller tip clearance results in reduced tip leakage flow with overall 37 percent drop in leakage flow with each reduction in tip clearance.

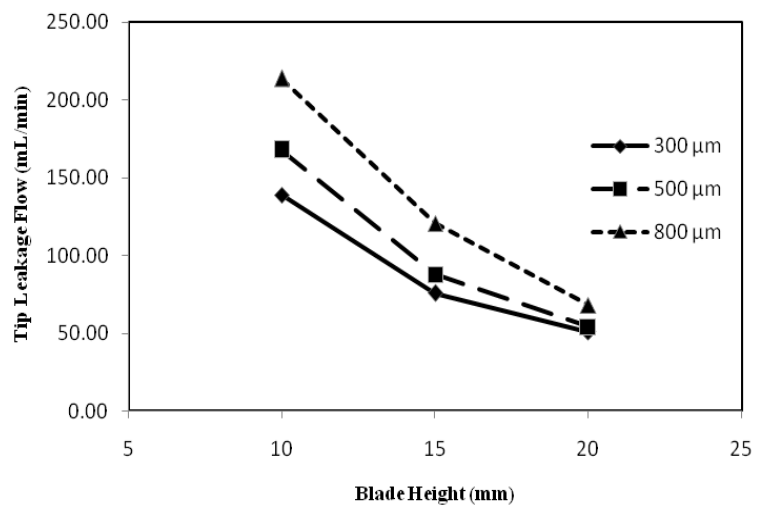

Fig. 8: Mean leakage flow through the impeller tip clearance versus impeller blade height at rotating speed $2000 \mathrm{rpm}$ outflow $5 \mathrm{~L} / \mathrm{min}$.

Table 4: Data of average leakage flow $(\mathrm{L} / \mathrm{min})$ at rotating speed $2000 \mathrm{rpm}$ and outflow $5 \mathrm{~L} / \mathrm{min}$.

\begin{tabular}{ccccc}
\hline $\begin{array}{c}\text { Average Leakage } \\
\begin{array}{c}\text { Flow } \\
(\mathrm{mL} / \mathrm{min})\end{array}\end{array}$ & \multicolumn{4}{l}{ Blade Height $(\mathrm{mm})$} \\
\hline $\begin{array}{c}\text { Tip Clearance } \\
(\mu \mathrm{m})\end{array}$ & 10 & 15 & 20 & Mean \\
\hline 300 & 139.02 & 75.86 & 50.88 & 88.59 \\
500 & 167.59 & 87.82 & 54.23 & 127.70 \\
800 & 213.85 & 120.72 & 68.12 & 167.28 \\
Mean & 173.48 & 94.80 & 50.88 & \\
\hline
\end{tabular}

It can be seen that there are apparent flow behaviour affected by the studied parameters from the leakage flow perspective. Higher tip leakage flow corresponds with lower blade height probably due to the volumetric loses as the gap is a more significant proportion of the impeller blade when the blade height is small. Similar behaviour can be seen for all three tip clearances. As for tip clearance, the smaller tip clearance results in reduced tip leakage flow. This is quite an expected outcome as a smaller gap increases the obstruction to flow through the impeller clearance resulting in a reduced leakage flow.

\subsection{Pressure Head}

The output pressure produced by the numerical simulation is illustrated in Fig. 1 and tabulated in Table 5 for the corresponding blade height of each tip clearance. Generally, pressure output increases with each increment of blade height although showing reduced increase in pressure at higher blade height. However, the behaviour of increasing tip clearance exhibits a reducing output pressure as the tip clearance increase from $300 \mu \mathrm{m}$ to 800 $\mu \mathrm{m}$. It is an expected behaviour as the highest pressure was produced with smallest gap and lowest pressure with largest gap probably due to the increase likelihood of leakage flow through the tip clearance for the larger tip clearances.

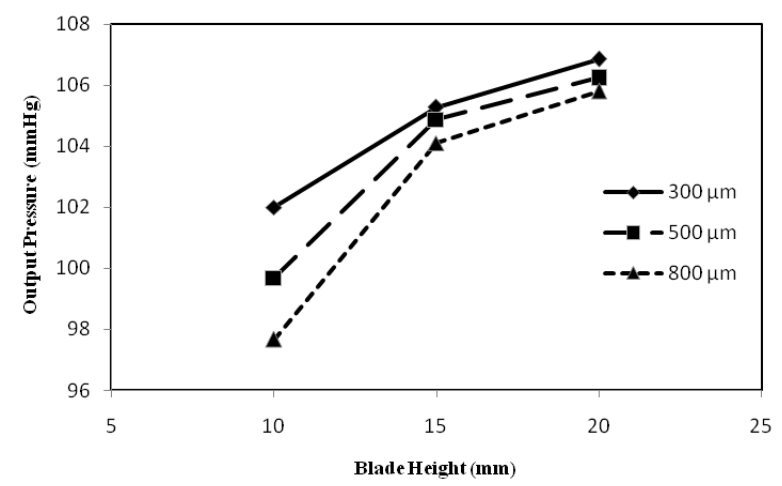

Fig. 1: Output Pressure for varying tip clearance versus impeller blade height at rotating speed $2000 \mathrm{rpm}$ outflow $5 \mathrm{~L} / \mathrm{min}$.

The lowest output pressure among the blade heights of the studied models is the $10 \mathrm{~mm}$ blade height variant with a mean pressure of $99.8 \mathrm{mmHg}$. Among the varying tip clearances of this blade height, the model with the largest tip clearance of $800 \mu \mathrm{m}$ produces the lowest pressure and with decreasing tip clearance output pressure appears to increase. The highest output pressure is the tallest of studied blade height of $20 \mathrm{~mm}$ with a mean pressure of $106.3 \mathrm{mmHg}$, sharing similar behaviour between varying tip clearance. A tighter tip clearance results in increasing pressure. Although the use of larger tip clearances ensure lesser blood damage potential, large tip clearance would contribute to loses in performance in the impeller evidently by the increasing leakage flow. 
Table 5: Data of output pressure $(\mathrm{mmHg})$ at rotating speed $2000 \mathrm{rpm}$ and outflow $5 \mathrm{~L} / \mathrm{min}$.

\begin{tabular}{ccccc}
\hline $\begin{array}{c}\text { Outlet Pressure } \\
(\mathrm{mmHg})\end{array}$ & \multicolumn{4}{c}{ Blade Height $(\mathrm{mm})$} \\
\hline $\begin{array}{c}\text { Tip Clearance } \\
(\mu \mathrm{m})\end{array}$ & 10 & 15 & 20 & Mean \\
300 & 102.01 & 105.29 & 106.86 & 104.72 \\
500 & 99.69 & 104.88 & 106.23 & 103.60 \\
800 & 97.67 & 104.11 & 105.80 & 102.53 \\
Mean & 99.79 & 104.76 & 106.30 & \\
\hline
\end{tabular}

Blade height has more apparent effect on performance likely due to the increase in blade area with increasing blade height; allowing better transfer of energy from the impeller to the fluid. The pump head increases with increasing blade height. The increase in blade height had been explained in other studies due to decrease the meridional velocity of the fluid, which in turn raises the pressure head since the outlet tangential velocity and the outlet blade angle remain constant [31]. From all these model variants, the pressure head generated in general are within the range of the required pressure head of 100 $\mathrm{mmHg}$ (97 $\mathrm{mmHg}$ to $106 \mathrm{mmHg}$ ). With the current geometry of the design, the blood pump would meet the pressure head required.

\subsection{Pump Efficiency}

Hydraulic efficiency is an important consideration as it gauges how well the blood pump operates; how much power on the impeller needed to generate flow to overcome the pressure at the pump outlet[32]. Hydraulic efficiency is the ratio of hydrodynamic power output to work of the shaft and is illustrated in equation 5:

$$
\eta=\frac{P Q}{T \omega}
$$

where $\mathrm{P}$ is the pressure head, $\mathrm{Q}$ is the pump flow rate, $\mathrm{T}$ in the torque acting on the impeller at its axis, and $\omega$ is the blood pump rotational speed in $\mathrm{rad} / \mathrm{s}$.

Fig. 2 shows the efficiency plot against the blade height for the varying tip clearance. From the figure, the range of the hydraulic efficiency varies between 55 to 58 percent. As shown in

Table 6, there is little significant differences across tip clearance and blade height levels, with the exception of the lowest blade height $(10 \mathrm{~mm})$ with the largest tip clearance showing the least value of 57.2 percent. The highest blood pump efficiency smallest tip clearance, 300 $\mu \mathrm{m}$ at an average of 58.3 percent. The lowest efficiency is evidently the variant with the largest tip clearance of 800 $\mu \mathrm{m}$ with efficiency of 57.7 percent in overall. From the figure, it can be seen that by increasing the blade height bears minor significance in affecting pump efficiency although otherwise can be said for varying tip clearance. Larger tip clearances has resulted in reduced efficiency probably due to the higher leakage flow to occur contributing to volumetric loses, thus affecting efficiency [32]. This is rather true in this study that the model variants with larger gaps tend produce lower pressure and reduced efficiency although slightly in addition to the higher tip leakage flow.

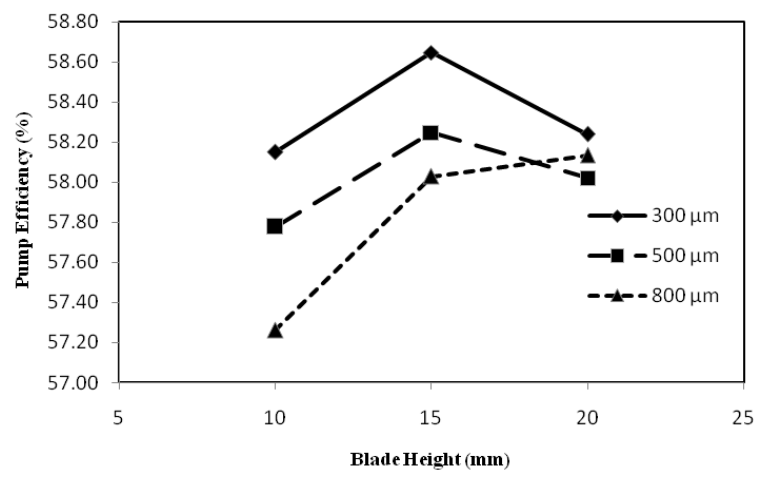

Fig.2: The curve of efficiency against blade height at rotating speed $2000 \mathrm{rpm}$ outflow $5 \mathrm{~L} / \mathrm{min}$

Table 6: Data of average leakage flow (L/min) at rotating speed $2000 \mathrm{rpm}$ and outflow $5 \mathrm{~L} / \mathrm{min}$.

\begin{tabular}{|c|c|c|c|c|}
\hline $\begin{array}{c}\text { Average } \\
\text { Leakage } \\
\text { Flow }\end{array}$ & \multicolumn{3}{|c|}{ Blade Height (mm) } & \\
\hline $\begin{array}{c}\text { Tip } \\
\text { Clearance } \\
(\mu \mathrm{m})\end{array}$ & 10 & 15 & 20 & Mean \\
\hline 300 & 58.15 & 58.64 & 58.23 & 58.3 \\
\hline 500 & 57.78 & 58.24 & 58.02 & 58.0 \\
\hline 800 & 57.26 & 58.02 & 58.13 & 57.8 \\
\hline Mean & 57.7 & 58.3 & 58.1 & \\
\hline
\end{tabular}

\subsection{Optimum Model Evaluation Method}

With several model variants from two design factors, tip clearance and impeller blade height, evaluation of which model would be the best one was quite difficult to be done. Therefore, a selection method typically for product design process was used. This method can easily rate the best model whenever there are several models that has to be selected for prototyping or manufacturing. This method identified all results and yields the best model available from variants depending on which parameters were deemed most important; in this study, the highest weighting was given to the Haemolysis Index at $35 \%$, while Pump Efficiency was set at $10 \%$.

In Table 7 , the rank for each parameter, summation of rank value and final ranking is tabulated. The results obtained from each parameter were ranked accordingly for the nine model variants; the best of each parameter were ranked as 1 while the worse is ranked as 9. Then the next step would further ranked by weighting. The numerical value of each parameter was multiplied to a predetermined fraction of $100 \%$ to reflect which parameters were important to the working of a mechanical blood pump. The more important parameter was given higher weighting compared to less important parameter which can be referred in Table 2. The final score for the model selection shows that model variant $(800 \mu \mathrm{m}, 15 \mathrm{~mm})$ scored the best in overall with a score of 
8.85 follow by model $(800 \mu \mathrm{m}, 10 \mathrm{~mm})$ scoring rank 9.98 and model $(500 \mu \mathrm{m} 10 \mathrm{~mm})$ scoring rank 9.43. In this study, only two design factors were considered - tip clearance and impeller blade height; even if more design factors were included, by using scoring method, selection of a champion with the best performing model can be performed with ease. Out of nine models, the one selected due to the best scoring was model $15 \mathrm{~mm}$ blade height with $800 \mu \mathrm{m}$ tip clearance.

Table 7: Scoring for model variants for haemolysis index (HI), leakage flow (LF), pressure output (Pout) and Pump efficiency leakage $(\eta)$

\begin{tabular}{|c|c|c|c|c|c|c|c|c|c|c|c|c|c|c|c|}
\hline \multirow{2}{*}{ 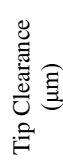 } & \multirow{2}{*}{ 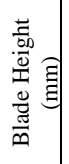 } & \multirow[b]{2}{*}{ Value } & \multicolumn{2}{|l|}{$\mathrm{HI}$} & \multicolumn{3}{|c|}{ LF } & \multicolumn{3}{|c|}{$P_{\text {out }}$} & \multicolumn{3}{|c|}{$\eta$} & \multirow{2}{*}{$\begin{array}{c}\text { Overall } \\
\text { Rank }\end{array}$} & \multirow{2}{*}{$\begin{array}{l}\text { FINAL } \\
\text { RANK }\end{array}$} \\
\hline & & & Rank & $35 \%$ & Value & Rank & $30 \%$ & Value & Rank & $25 \%$ & Value & Rank & $10 \%$ & & \\
\hline \multirow{3}{*}{ \&్ల } & 10 & 0.116 & 7 & 2.45 & 139.0 & 3 & 0.90 & 102.0 & 7 & 1.75 & 58.15 & 3 & 5.82 & 10.92 & 7 \\
\hline & 15 & 0.134 & 9 & 3.15 & 75.9 & 6 & 1.80 & 105.3 & 4 & 1.00 & 58.64 & 6 & 5.86 & 11.81 & 9 \\
\hline & 20 & 0.128 & 8 & 2.80 & 50.9 & 9 & 2.70 & $\underline{106.9}$ & $\underline{1}$ & $\underline{0.25}$ & 58.23 & 9 & 5.82 & 11.57 & 8 \\
\hline \multirow{3}{*}{8} & 10 & 0.016 & 3 & 1.05 & 167.6 & 2 & 0.60 & 99.7 & 8 & 2.00 & 57.77 & 2 & 5.78 & 9.43 & 3 \\
\hline & 15 & 0.055 & 6 & 2.10 & 87.8 & 5 & 1.50 & 104.9 & 5 & 1.25 & 58.24 & 5 & 5.82 & 10.67 & 6 \\
\hline & 20 & 0.043 & 5 & 1.75 & 54.0 & 8 & 2.40 & 106.2 & 2 & 0.50 & 58.02 & 8 & 5.80 & 10.45 & 5 \\
\hline \multirow{3}{*}{$\stackrel{\infty}{~}$} & 10 & 0.015 & 2 & 0.70 & $\underline{213.8}$ & $\underline{1}$ & $\underline{0.30}$ & 97.7 & 9 & 2.25 & $\underline{57.26}$ & $\underline{1}$ & $\underline{5.73}$ & 8.98 & 2 \\
\hline & 15 & $\underline{0.010}$ & $\underline{1}$ & $\underline{0.35}$ & 120.7 & 4 & 1.20 & 104.1 & 6 & 1.50 & 58.02 & 4 & 5.80 & $\underline{8.85}$ & $\underline{1}$ \\
\hline & 20 & 0.030 & 4 & 1.40 & 68.0 & 7 & 2.10 & 105.8 & 3 & 0.75 & 58.13 & 7 & 5.81 & 10.06 & 4 \\
\hline
\end{tabular}

\section{Conclusion}

A steady state Newtonian blood flow in a three dimensional centrifugal blood pump was investigated numerically. The effects of two design factors of the blood pump were studied: the impeller blade height and tip clearance between casing and impeller. Results from blood pump performance and blood damage potential were subjected to scoring method from which model variant $15 \mathrm{~mm}$ blade height with $800 \mu \mathrm{m}$ tip clearance was selected as the best configuration due to performance in two index categories from performance index results: pressure outlet and blood pump efficiency, while results from average flow leakage and haemolysis index were still good.

\section{Acknowledgement}

This work was funded in part by the IJN-UTM Cardiovascular Engineering Centre Flagship Research Grant (Grant No. Q.J130000.2409.01G66), and Malaysian Research University Research Grant Scheme (Q.J130000.3045.00M87).

\section{References}

[1] McCarthy, P. M., HeartMate implantable left ventricular assist device: bridge to transplantation and future applications., The Annals of thoracic surgery, Volume 59, no. 2 Suppl, (1995), pp. S46-51.

[2] Nakazawa, T., Takami, Y., Benkowski, R., Ohtsubo, S., Yukio, O., Tayama, E., Ohtsuka, G., Niimi, Y., Glueck, J., Sueoka, A., Schmallegger,
H., Schima, H., Wolner, E., and Nosé, Y., Development and Initial Testing of a Permanently Implantable Centrifugal Pump, Artificial Organs, Volume 21, no. 7, (1997), pp. 597-601.

[3] DeBakey, M. E., The Odyssey of the Artificial Heart, Artificial Organs, Volume 24, no. 6, (2000), pp. 405-411.

[4] Lloyd-Jones, D., Adams, R. J., Brown, T. M., Carnethon, M., Dai, S., De Simone, G., Ferguson, T. B., Ford, E., Furie, K., Gillespie, C., Go, A., Greenlund, K., Haase, N., Hailpern, S., Ho, P. M., Howard, V., Kissela, B., Kittner, S., Lackland, D., et al., Heart disease and stroke statistics--2010 update: a report from the American Heart Association., Circulation, Volume 121, no. 7, (2010), pp. e46-e215.

[5] Roger, V. L., Epidemiology of Heart Failure, Circulation Research, Volume 113, no. 6, (2013), pp. 646-659.

[6] Fraser, K. H., Taskin, M. E., Griffith, B. P., and $\mathrm{Wu}, \mathrm{Z}$. J., The use of computational fluid dynamics in the development of ventricular assist devices., Medical engineering \& physics, Volume 33, no. 3, (2011), pp. 263-80.

[7] Djerroud, M., Dituba Ngoma, G., and Ghie, W., Numerical Identification of Key Design Parameters Enhancing the Centrifugal Pump Performance: Impeller, Impeller-Volute, and Impeller-Diffuser, ISRN Mechanical Engineering, Volume 2011, (2011), pp. 1-16.

[8] J.B., A., H.G., W., P.E., A., J.C., M., D.B., O., G., B., Anderson, J. B., Wood, H. G., Allaire, P. E., 
McDaniel, J. C., Olsen, D. B., and Bearnson, G., Numerical studies of blood shear and washing in a continuous flow ventricular assist device, ASAIO Journal, Volume 46, no. 4, (2000), pp. 486-494.

[9] Wu, J., Paden, B. E., Borovetz, H. S., and Antaki, J. F., Computational fluid dynamics analysis of blade tip clearances on hemodynamic performance and blood damage in a centrifugal ventricular assist device., Artificial organs, Volume 34, no. 5, (2010), pp. 402-11.

[10] Graefe, R., Henseler, A., and Steinseifer, U., Multivariate Assessment of the Effect of Pump Design and Pump Gap Design Parameters on Blood Trauma., Artificial organs, Volume 40, no. 6, (2016), pp. 568-76.

[11] Behbahani, M., Behr, M., Hormes, M., Steinseifer, U., Arora, D., Coronado, O., and Pasquali, M., A review of computational fluid dynamics analysis of blood pumps, European Journal of Applied Mathematics, Volume 20, no. 4, (2009), pp. 363-397.

[12] Carswell, D., Hilton, A., Chan, C., McBride, D., Croft, N., Slone, A., Cross, M., and Foster, G., Development of a radial ventricular assist device using numerical predictions and experimental haemolysis., Medical engineering \& physics, Volume 35, no. 8, (2013), pp. 1197-203.

[13] Klabunde, R. E., Cardiovascular Physiology Concepts. Lippincott Williams \& Wilkins, (2005).

[14] Wood, H. G., Throckmorton, A. L., Untaroiu, A., and Song, X., The medical physics of ventricular assist devices, Reports on Progress in Physics, Volume 68, no. 3, (2005), pp. 545-576.

[15] Spiel, A. O., Gilbert, J. C., and Jilma, B., Von Willebrand Factor in Cardiovascular Disease, Circulation, Volume 117, no. 11, (2008), p. 1449 LP-1459.

[16] Nishida, M., Asztalos, B., Yamane, T., Masuzawa, T., Tsukiya, T., Endo, S., Taenaka, Y., Miyazoe, Y., Ito, K., and Konishi, Y., Flow Visualization Study to Improve Hemocompatibility of a Centrifugal Blood Pump, Artificial Organs, Volume 23, no. 8, (1999), pp. 697-703.

[17] Moazami, N., Fukamachi, K., Kobayashi, M., Smedira, N. G., Hoercher, K. J., Massiello, A., Lee, S., Horvath, D. J., and Starling, R. C., Axial and centrifugal continuous-flow rotary pumps: a translation from pump mechanics to clinical practice., The Journal of heart and lung transplantation: the official publication of the International Society for Heart Transplantation, Volume 32, no. 1, (2013), pp. 1-11.

[18] Andersson, B., Andersson, R., Hakansson, L., Mortensen, M., Sudiyo, R., and van Wachem, B., Computational fluid dynamics for engineers, 1 st ed. Cambridge University Press, (2012).

[19] Wu, Y., Allaire, P., Tao, G., and Olsen, D., Study of pressure estimation for a human circulatory system with a LVAD, in 2006 American Control Conference, (2006), p. 6 pp.

[20] Giersiepen, M., Wurzinger, L. J., Opitz, R., and Reul, H., Estimation of shear stress-related blood damage in heart valve prostheses--in vitro comparison of 25 aortic valves., The International journal of artificial organs, Volume 13, no. 5, (1990), pp. 300-6.

[21] Bludszuweit, C., Three-Dimensional Numerical Prediction of Stress Loading of Blood Particles in a Centrifugal Pump, Artificial Organs, Volume 19, no. 7, (1995), pp. 590-596.

[22] Grigioni, M., Daniele, C., Morbiducci, U., D’Avenio, G., Di Benedetto, G., and Barbaro, V., The power-law mathematical model for blood damage prediction: Analytical developments and physical inconsistencies, Artificial Organs, Volume 28, no. 5, (2004), pp. 467-475.

[23] Taskin, M. E., Fraser, K. H., Zhang, T., Gellman, B., Fleischli, A., Dasse, K. A., Griffith, B. P., and Wu, Z. J., Computational characterization of flow and hemolytic performance of the UltraMag blood pump for circulatory support., Artificial organs, Volume 34, no. 12, (2010), pp. 1099113.

[24] Ibrahim, M. H. I., Muhamad, N., Sulong, A. B., Jamaludin, K. R., Ahmad, S., and Nor, N. H. M., Single Performance Optimization of Micro Metal Injection Molding for the Highest Green Strength by Using Taguchi Method, International Journal of Integrated Engineering, Volume 2, no. 1, (2010), pp. 35-44.

[25] Kang, H.-S. and Kim, Y.-J., Optimal design of impeller for centrifugal compressor under the influence of one-way fluid-structure interaction, Journal of Mechanical Science and Technology, Volume 30, no. 9, (2016), pp. 3953-3959.

[26] Daud, Z., Hijab, M., Bakar, A., Rosli, M. A., Ridzuan, B., and Aliyu, R., Application of response surface methodology ( RSM ) to optimize COD and ammoniacal nitrogen removal from leachate using moringa and zeolite mixtures, International Journal of Integrated Engineering, Volume 10, no. 1, (2018), pp. 142-149.

[27] Ulrich, K. and Eppinger, S., Product Design and Development, 5th edition, Karl Ulrich, Steven Eppinger, eBook - Amazon.com, 5th ed. McGrawHill, (2011).

[28] Xiao, A., Park, S. S., and Freiheit, T., A Comparison of Concept Selection in Concept Scoring and Axiomatic Design Methods, Proceedings of the Canadian Engineering Education Association. (2011).

[29] Day, S. W., Lemire, P. P., Flack, R. D., and McDaniel, J. C., Effect of Reynolds Number on Performance of a Small Centrifugal Pump, in Volume 1: Fora, Parts A, B, C, and D, (2003), pp. 1893-1899.

[30] Apel, J., Neudel, F., and Reul, H., Computational 
fluid dynamics and experimental validation of a microaxial blood pump, ASAIO journal (American Society for Artificial Internal Organs : 1992), Volume 47, no. 5, (1992), pp. 552-8.

[31] Djerroud, M., Ngoma, G. D., and Ghie, W., Numerical Identification of Key Design Parameters Enhancing the Centrifugal Pump Performance: Impeller, Impeller-Volute, and
Impeller-Diffuser, ISRN Mechanical Engineering, (2011), pp. 1-16.

[32] Wu, H., Wang, Z., and Lv, X., Design and Simulation of Axial Flow Maglev Blood Pump, International Journal of Information Engineering and Electronic Business(IJIEEB), Volume 3, no. 2, (2011), pp. 42-48. 